\title{
Language, learning, and memory in children with and without single-suture craniosynostosis
}

\author{
Kathleen A. Kapp-Simon, PhD,,2 Erin Wallace, PhD, ${ }^{3}$ Brent R. Collett, $\mathrm{PhD},{ }^{3,4}$ \\ Mary Michaeleen Cradock, PhD, ${ }^{5}$ Canice E. Crerand, PhD, ${ }^{6,7}$ and Matthew L. Speltz, $\mathrm{PhD}{ }^{3,4}$
}

\begin{abstract}
${ }^{1}$ Cleft-Craniofacial Center, Shriners Hospitals for Children, Chicago; and ${ }^{2}$ Craniofacial Center, Department of Surgery, University of Illinois at Chicago, Illinois; ${ }^{3}$ Seattle Children's Research Institute; and ${ }^{4}$ Department of Psychiatry and Behavioral Medicine, University of Washington School of Medicine, Seattle, Washington; '5epartment of Psychology, St. Louis Children's Hospital, St. Louis, Missouri; ${ }^{6}$ Center for Biobehavioral Health, The Research Institute at Nationwide Children's Hospital; and ${ }^{7}$ Departments of Pediatrics and Plastic Surgery, The Ohio State University College of Medicine, Columbus, Ohio
\end{abstract}

\begin{abstract}
OBJECTIVE The language and memory functions of children with and without single-suture craniosynostosis (SSC) were compared at school age (mean 7.45 years, standard deviation [SD] 0.54 years). The children in this cohort were originally recruited in infancy and prior to cranial surgery for those with SSC.

METHODS Individual evaluations of 179 school-aged children with SSC and 183 controls were conducted $(70 \%$ of the original cohort) using standardized measures of language, learning, and memory. Parents participated in an interview about specialized education interventions and school progress. Parents and teachers completed questionnaires about language development.
\end{abstract}

RESULTS Children with SSC (cases) obtained lower scores than controls on all measures. The adjusted differences in language, learning, and memory scores were modest, with SD ranging from 0.0 to -0.4 ( $p$ values ranged from 0.001 to 0.99). Censored normal regression was used to account for intervention services received prior to the school-age evaluation; this increased case-control differences (SD range 0.1 to $-0.5, p$ value range 0.001 to 0.50 ). Mean scores for cases in each SSC diagnostic group were lower than those for controls, with the greatest differences observed among children with unilateral coronal craniosynostosis.

CONCLUSIONS Children with SSC continue to show poorer performance than controls on language, learning, and memory tasks at early elementary school age, even when controlling for known confounders, although mean differences are small. Multidisciplinary care, including direct psychological assessment, for children with SSC should extend through school age with a specific focus on language and conceptual learning, as these are areas of potential risk. Future research is needed to investigate language, memory, and learning for this population during the middle to high school years.

http://thejns.org/doi/abs/10.3171/2015.9.PEDS15238

KEY WORDS craniosynostosis; language; learning; memory; neuropsychological functioning; craniofacial

$\mathrm{P}$ REMATURE fusion of one of the major cranial sutures (sagittal, metopic, coronal, or lambdoid), known as single-suture craniosynostosis (SSC), occurs in approximately 1 in 1700 to 1 in 2500 live births. ${ }^{17,42}$ Studies of infants with SSC have shown that affected children demonstrate modest delays in motor and cognitive development relative to test norms..$^{22,24}$ In the largest infant study to date, we followed children with and without SSC from infancy to age 3 years and found that children with
SSC scored from 0.25 to 0.50 standard deviations lower than unaffected control children in cognitive, language, and motor development. ${ }^{44-46}$ The few studies of older children indicate that, as a group, global intelligence for children with SSC is within the average range compared with test norms. However, there is a downward shift in the distribution of IQ scores among children with SSC, with more children than expected scoring at the lower end of the distribution and fewer scoring above average. ${ }^{9,15,24,43}$

ABBREVIATIONS CCC-2 = Children's Communication Checklist-2; CGH = comparative genomic hybridization; CMS = Children's Memory Scale; NEPSY-II = NEPSY-II: A Developmental Neuropsychological Assessment; PDI = Psychomotor Development Index; SES = socioeconomic status; SIDI = Social Interaction Difference Index; SSC = single-suture craniosynostosis; Token Test-II = Token Test for Children, Second Edition; WISC-IV = Wechsler Intelligence Scale for Children-IV; WPT = Wonderlic Personnel Test.

SUBMITTED April 17, 2015. ACCEPTED September 11, 2015.

INCLUDE WHEN CITING Published online January 1, 2016; DOI: 10.3171/2015.9.PEDS15238. 
These findings, along with studies of related neuropsychological functions, have led researchers to suggest that children with SSC are at greater risk of learning problems than unaffected peers. ${ }^{20,22,24,31,36,43}$ However, it is not yet clear which specific areas of learning are at greatest risk.

Language and memory are specific skills that are critical for academic success, and several studies have reported that some children with SSC-perhaps one-third or more-have deficits in this area. ${ }^{4,23,26,34,41}$ However, other studies have found little evidence of language or memory deficits in children with SSC, ${ }^{6,15}$ or have reported much smaller percentages of affected children. ${ }^{8,9,48}$ Furthermore, most investigations of these outcomes have not used control groups to adjust for the potentially strong influence of socioeconomic variables on language and other specific skills. ${ }^{16}$

In the present study, we examined language and memory skills in children with SSC relative to demographically similar, unaffected controls, using a broad, standardized battery of clinician-administered tests, as well as parent and teacher report measures. The study builds on previously published work from this cohort when the subjects were infants, and on a recent paper showing modest differences between children with SSC and unaffected controls on measures of global intelligence and academic achievement at elementary school age. ${ }^{43}$ We hypothesized that children with SSC would score lower than unaffected children on measures of language and memory. Based on previous studies showing subgroup differences among cases, ${ }^{9,43}$ we also explored differences as a function of suture fusion location. In secondary analyses, we examined the effects of early interventions (e.g., speech and language therapy, special education services) on case-control differences, and whether findings were altered when accounting for possible attrition bias and the exclusion of cases with known or probable genetic mutations.

\section{Methods}

\section{Study Design}

Data are derived from our fourth evaluation of children with SSC (cases) and a comparison group of unaffected children (controls) who were part of a multisite longitudinal study of neurobehavioral development (see Starr et al..$^{45}$ for details regarding study design and recruitment). Participants were initially enrolled between January 2002 and December 2006, prior to cranioplasty surgery for the case participants. Approximately $90 \%$ of the children were 7 years of age and in first or second grade at the time of the current evaluation.

\section{Cases}

Patients were referred to this study by their surgeon or pediatrician at the time of diagnosis and prior to surgical intervention. Study sites included Seattle Children's Hospital (Washington); Northwestern University, enrolling children through Children's Memorial Hospital (Illinois), and, after January 2006, Children's Hospital of Philadelphia (Pennsylvania); Children's Health Care of Atlanta (Georgia); and St. Louis Children's Hospital (Missouri).

Eligible infants included those who 1) had isolated sag- ittal, metopic, unilateral coronal, or unilateral lambdoid craniosynostosis; 2) had yet to undergo cranial vault surgery; and 3) were $\leq 30$ months of age at the time of recruitment. Premature infants ( $<34$ weeks); infants with a major medical or neurological condition (e.g., cardiac defects, cerebral palsy, etc.); and infants with more than 3 extracranial minor malformations $\mathrm{s}^{30}$ or any other major malformation were excluded. For patients for whom parents gave consent, we collected biospecimens and analyzed genetic data by array comparative genomic hybridization (CGH) and candidate and gene resequencing (for details see Cunningham et al. $\left.{ }^{14}\right)$. Children with SSC who had a genetic variant (including a known or probable causal mutation for craniosynostosis) were eligible if they had no phenotypic features of a known syndrome and otherwise met all inclusion criteria.

We enrolled 270 cases (84\% of those eligible), 4 of which were later found to be ineligible. Among the 266 infants seen at baseline, 182 children (68\%) had a schoolage study visit and at least 1 valid outcome score among the measures described below. Mean age at surgery was 9.1 months. Most children underwent surgery by age 12 months (80\%) and almost all children by 24 months (98\%). Three patients with metopic SSC had not undergone cranioplasty by age 7 years and were excluded from the current analyses. Results of genetic testing were available for 173 of 179 cases participating in the school age evaluation.

\section{Controls}

Infants were eligible as controls if they had no known craniofacial anomaly and met none of the exclusion criteria for cases. Controls were recruited through pediatric practices, birthing centers, and announcements in publications of interest to parents of newborns. Controls were frequency-matched to cases on potential demographic confounders, including child age at enrollment and sex, family socioeconomic status (SES; assessed via the Hollingshead Index ${ }^{21}$ ), and race/ethnicity.

Among the 257 controls seen at baseline, 183 (71\%) were assessed at the school age visit and had at least 1 valid outcome score.

\section{Measures \\ Wechsler Intelligence Scale for Children-IV}

The Vocabulary and Similarities subtests from the Wechsler Intelligence Scale for Children-IV (WISC-IV) ${ }^{50}$ Verbal Comprehension Index were used to assess word knowledge and verbal reasoning. Based on these scores, a composite prorated standard score was generated using the WISC-IV scoring software. The Verbal Comprehension Index has a norm-referenced mean of 100 and SD of 15.

\section{Children's Memory Scale}

Two subtests from the Children's Memory Scale (CMS), ${ }^{11}$ Stories and Word Lists, were administered to assess immediate, delayed, and delayed recognition memory. For the Stories subtest, children are asked to repeat a story verbatim and receive credit for story elements remembered and story themes articulated. For the Word Lists subtest, children are asked to remember a list of 14 unre- 
lated words over 5 trials. After each trial, the words missed on the previous trial are repeated, and the child is asked to recall the entire list. A learning score is calculated based on the child's progress in learning the list of words. Both subtests have a delayed recall component that assesses memory after a delay of 30-35 minutes. Following the delayed recall, children are given choices and asked to indicate if that information was presented previously (delayed recognition). For each subtest, scaled scores are generated with a norm-referenced mean of 10 and SD of 3.

\section{NEPSY-II: A Developmental Neuropsychological Assessment}

Verbal fluency was assessed by administering the NEPSY-II: A Developmental Neuropsychological Assessment (NEPSY-II) ${ }^{25}$ Word Generation subtest. Children are asked to provide as many words within a category (semantic) or that begin with a specific letter (initial letter) as they are able within a specified time frame. Standardized scores with a mean of 10 and SD of 3 are generated separately for the semantic and initial letter subscales.

\section{Token Test for Children, Second Edition}

The Token Test for Children, Second Edition (Token Test-II) ${ }^{33}$ assesses receptive language, sequential memory, syntax, and prepositional concepts. Children are asked to follow up to 46 commands of increasing difficulty. A single standardized score with a mean of 100 and SD of 15 is generated for this test.

\section{Children's Communication Checklist-2}

Parents and teachers completed the Children's Communication Checklist-2 (CCC-2), 7 a measure of children's communication skills that assesses a child's competence in using language based on syntax, morphology, semantics, and pragmatics of communication. The General Communication Composite score is a summary measure of a child's communication skills and has a mean standard score of 100 with an SD of 15 . The Social Interaction Difference Index (SIDI) helps determine if a child has a pragmatic or language disorder. Children with low scores (less than -10) on the SIDI may show pragmatic deficits due to poor nonverbal communication, initiation skills, or social relatedness while children with high SIDI scores (greater than +10 ) are suspect for a language disorder. Absolute values of the SIDI were used in analyses to detect differences at either end of the scale.

\section{Wonderlic Personnel Test}

The Wonderlic Personnel Test (WPT) $)^{51}$ is a timed, norm-referenced screening measure of general intelligence in adolescents and adults. The WPT has good reliability and correlates well with clinician-administered measures (e.g., the Wechsler scales). The WPT was administered to mothers of participating children, allowing us to control for maternal IQ in case versus control group comparisons.

\section{Caregiver Interview}

Primary caregivers completed a semistructured interview to collect information on child medical history, in- cluding diagnosis of hearing loss, speech and language delays, and learning problems. When relevant, we collected information on interventions that children received in the community, including early intervention services (e.g., speech and language therapy or hearing-impaired services), occupational or physical therapy, behavioral interventions, response to intervention services, or special education.

\section{Procedures}

We obtained informed consent for each enrolled subject following the protocols approved by the institutional review boards of each participating institution.

All testing sessions were video-recorded, and all test administrations were independently scored by a second psychometrist. Scoring errors were recorded, and disagreements between psychometrists were resolved by one of the psychologist investigators (K.K.S., B.R.C., or M.L.S.). Resolved scores were used for all analyses. Among all administrations of the measures reported here, $84 \%$ of the WISC-IV administrations were error free, as were $77 \%$ of CMS, $84 \%$ of the NEPSY-II, and $92 \%$ of the Token Test. All standardized tests demonstrated acceptable reliability and validity.7,11,25,33,50,51

A caregiver interview was used to update family demographic information and medical history and to provide information on interventions that the child was currently receiving or had received since their last assessment at age 3 (e.g., speech or language therapy). In keeping with ethical standards for the use of psychometric tests in research with minors, ${ }^{27}$ parents were offered a written summary of their child's test results; they were encouraged to share this information with their child's pediatrician or teacher.

\section{Statistical Analysis}

The distributions of demographic characteristics and language, learning, and memory scores were calculated separately for cases and controls. Because approximately one-third of the children from the original study were lost to attrition, we also compared the demographic and neurodevelopmental characteristics of children seen at the school-age visit to those lost to follow-up.

Linear regression with robust standard errors was used to estimate differences in language, learning, and memory scores between cases and controls, with corresponding 95\% confidence intervals. All analyses were adjusted for the child's age at assessment (in months, continuous), sex, family SES ${ }^{21}$ (composite score, continuous), and maternal IQ (continuous, measured at baseline by the WPT). We used logistic regression with robust standard errors to compare the proportion of cases and controls reporting a current or prior history of speech or language therapy, hearing problems, hearing services, or a diagnosis of a language disorder. Because both negative and positive SIDI scores can indicate communication problems, SIDI scores were converted to absolute values for all analyses.

We also evaluated whether language, learning, and memory scores differed by the site of the affected suture (sagittal, metopic, unilateral coronal, and unilateral lambdoid synostosis) using linear regression with robust standard errors and with controls considered the referent cat- 
egory. Overall group differences were tested using Wald tests.

Several sensitivity analyses were performed. To explore the impact of selection bias due to study attrition, we repeated the primary analyses using inverse probability weighting..$^{40}$ This method places greater weight on observations from subjects seen at school age who are similar in terms of baseline characteristics to those of children lost to follow-up. Weights were estimated based on factors observed at baseline in all subjects, including date of birth, sex, race/ethnicity, prematurity $(<38$ weeks' gestation, coded yes/no), case status, suture diagnosis, parents' marital status, maternal IQ, study site, and scores from the Bayley Scales of Infant Development-2 (Psychomotor Development Index [PDI]) and the Preschool Language Scale-3 (auditory comprehension) completed at baseline. ${ }^{45}$ Finally, we repeated the primary analyses after excluding 19 children with SSC in whom known or probable causal mutations for craniosynostosis were detected through array comparative genomic hybridization and candidate and gene resequencing. ${ }^{14}$

We used censored normal regression to account for the possible effects of interim intervention on subsequent scores. We accounted for a number of interventions that may influence language, learning, and memory skills, including early developmental therapy; participation in state/county programs that monitor infant development; language, vision, and hearing therapy; physical or occupational therapy; mental health services; and special education services. This approach assumes that the scores of children who received intervention services are "leftcensored." In other words, while it is unknown what the child's "true score" would have been without intervention, it is assumed to be at least as low as their observed scores with intervention.

All analyses were performed using Stata version 12 (StataCorp LP).

\section{Results}

One hundred seventy-nine patients and 183 controls were seen at the early elementary school visit. Mean age at the time of the assessment for the patients was 7.5 years (range 6.9-9.5 years) and for controls was 7.4 years (range 7.0-11.1 years). Ninety-three percent of participants were in first or second grade. Children in both the case and control groups were predominantly male, identified as white or non-Hispanic ethnicity, and were of middle to upper SES (Hollingshead Categories I-II). ${ }^{21}$ Maternal IQ was slightly lower in patients (mean 106.0, SD 13.6) than controls (mean 109.7, SD 12.7), but the difference was not statistically significant (Table 1).

Thirty-one percent of patients and $29 \%$ of controls were lost to follow-up. Compared with children seen at school age, children who were lost to follow-up had lower Bayley PDI and maternal IQ scores at study baseline and were of lower SES (44\% Hollingshead Categories III-V ${ }^{21}$ vs $24 \%$ in participating subjects).

\section{Case-Control Differences}

Language, learning, and memory scores were consis-
TABLE 1. Demographic characteristics of children with and without SSC evaluated at age 7 years*

\begin{tabular}{|c|c|c|}
\hline & Controls & Patients \\
\hline Characteristic & $(n=183)$ & $(n=179)$ \\
\hline \multicolumn{3}{|l|}{ Age in years } \\
\hline$<7.5$ & $145(79.2)$ & $122(68.2)$ \\
\hline$\geq 7.5$ & $38(20.8)$ & $57(31.8)$ \\
\hline \multicolumn{3}{|l|}{ Sex } \\
\hline $\mathrm{F}$ & $68(37.2)$ & $66(36.9)$ \\
\hline M & $115(62.8)$ & $113(63.1)$ \\
\hline \multicolumn{3}{|l|}{ Grade† } \\
\hline$<1$ & $3(1.6)$ & $3(1.7)$ \\
\hline $1-2$ & $171(93.4)$ & $164(91.6)$ \\
\hline$\geq 3$ & $9(4.9)$ & $9(5.0)$ \\
\hline \multicolumn{3}{|l|}{ Race/ethnicity } \\
\hline Nonwhitef & $47(25.7)$ & $37(20.7)$ \\
\hline White & $136(74.3)$ & $142(79.3)$ \\
\hline \multicolumn{3}{|l|}{ SES } \\
\hline I (highest) & $53(29.0)$ & $42(23.5)$ \\
\hline II & $103(56.3)$ & $82(45.8)$ \\
\hline III & $14(7.7)$ & $33(18.4)$ \\
\hline IV & $10(5.5)$ & $20(11.2)$ \\
\hline V (lowest) & $3(1.6)$ & $2(1.1)$ \\
\hline Mean WPT (SD)§ & $25.0(6.5)$ & $23.0(6.9)$ \\
\hline \multicolumn{3}{|l|}{ Site } \\
\hline Seattle & $72(39.3)$ & $74(41.3)$ \\
\hline Chicagođ & $76(41.5)$ & $63(35.2)$ \\
\hline St. Louis & $9(4.9)$ & $18(10.1)$ \\
\hline Atlanta & $26(14.2)$ & $24(13.4)$ \\
\hline
\end{tabular}

* Values are number of children (\%) unless otherwise indicated.

$\dagger$ Grade level missing for 3 cases.

‡ Includes Hispanic/Latino ethnicity, Asian/Pacific Islander, Black/African American, and mixed races or ethnicities.

$\S$ Timed score; mean scores converted to the Wechsler Adult Intelligence Scale ${ }^{42}$ were 109.7 in controls (SD 12.7) and 106.0 in patients (SD 13.6).

I Includes children from Philadelphia, who were assessed by staff from the Chicago site.

tently lower in patients than controls, although adjusted case-control differences were modest in magnitude and ranged from 0.0 to $-0.4 \mathrm{SD}$ (Table 2). The largest relative case-control differences were for the WISC-IV Verbal Comprehension Index and the CMS, where scores in children with SSC were -0.2 to -0.3 SDs lower than in children without SSC in 8 of 9 subtests (p values range 0.0010.07). Case-control differences were similar in magnitude ( -0.2 to $-0.3 \mathrm{SD})$ for NEPSY-II Word Generation-Initial Letter and the CCC-2-Teacher General Communication Composite, but were less than -0.1 SD for the Token TestII, the NEPSY-II Initial Letter, and Parent CCC-2.

Forty-five patients (25\%) and 36 controls $(20 \%)$ reported prior or current speech or language therapy. After adjustment, patients were more likely than controls to undergo speech or language therapy, but these results may be due to chance (adjusted OR 1.42, 95\% CI 0.85-2.38). 
TABLE 2. Comparison of mean language, learning, and memory scores for children with and without SSC

\begin{tabular}{|c|c|c|c|c|c|c|c|c|}
\hline \multirow[b]{3}{*}{ Neurodevelopmental Test } & \multirow{2}{*}{\multicolumn{2}{|c|}{ Controls }} & \multirow{2}{*}{\multicolumn{2}{|c|}{ Patients }} & \multicolumn{4}{|c|}{ Cases vs Controls } \\
\hline & & & & & \multicolumn{2}{|l|}{ Unadjusted } & \multicolumn{2}{|l|}{ Adjusted $^{*}$} \\
\hline & No & Mean (SD) & No. & Mean (SD) & Difference $(95 \% \mathrm{Cl})$ & $p$ Value & Difference $(95 \% \mathrm{Cl})$ & $p$ Value \\
\hline Token Test & 177 & $104.8(12.5)$ & 173 & $101.9(12.9)$ & $-2.9(-5.5,-0.2)$ & 0.04 & $-1.1(-3.5,1.4)$ & 0.40 \\
\hline \multicolumn{9}{|l|}{ CMS } \\
\hline \multicolumn{9}{|l|}{ Stories } \\
\hline Immediate & 178 & $11.7(2.7)$ & 172 & $10.8(3.0)$ & $-0.9(-1.5,-0.3)$ & 0.003 & $-0.6(-1.2,-0.0)$ & 0.04 \\
\hline Delayed & 176 & $11.6(3.1)$ & 170 & $10.4(3.4)$ & $-1.3(-1.9,-0.6)$ & $<0.001$ & $-1.0(-1.6,-0.3)$ & 0.006 \\
\hline Delayed recognition & 177 & $10.9(2.6)$ & 169 & $10.7(2.7)$ & $-0.2(-0.8,0.3)$ & 0.40 & $-0.0(-0.5,0.5)$ & 0.99 \\
\hline Immediate thematic & 178 & $11.9(2.9)$ & 171 & $11.0(3.0)$ & $-.9(-1.5,-0.3)$ & 0.005 & $-0.7(-1.4,-0.1)$ & 0.05 \\
\hline Delayed thematic & 176 & $11.4(3.0)$ & 169 & $10.4(3.3)$ & $-1.0(-1.7,-0.3)$ & 0.003 & $-0.6(-1.4,-0.1)$ & 0.03 \\
\hline \multicolumn{9}{|l|}{ Word Lists } \\
\hline Learning & 174 & $10.2(2.8)$ & 169 & $9.4(2.9)$ & $-0.9(-1.5,-0.3)$ & 0.005 & $-0.6(-1.2,0.0)$ & 0.06 \\
\hline Delayed & 173 & $10.8(3.1)$ & 169 & $10.0(3.4)$ & $-0.9(-1.6,-0.2)$ & 0.01 & $-0.6(-1.3,0.1)$ & 0.07 \\
\hline Delayed recognition & 173 & $10.5(2.6)$ & 169 & $9.7(3.2)$ & $-0.8(-1.4,-0.2)$ & 0.01 & $-0.7(-1.3,0.0)$ & 0.04 \\
\hline \multicolumn{9}{|l|}{ NEPSY-II word generation } \\
\hline Semantic total score & 179 & $12.0(3.3)$ & 174 & $10.8(3.2)$ & $-1.1(-1.8,-0.5)$ & 0.001 & $-0.8(-1.5,-0.2)$ & 0.01 \\
\hline Initial letter total score & 179 & $9.7(2.6)$ & 175 & $9.3(2.8)$ & $-0.4(-1.0,0.1)$ & 0.15 & $-0.2(-0.8,0.4)$ & 0.53 \\
\hline \multicolumn{9}{|l|}{ WISC-IV } \\
\hline Verbal comprehension & 183 & $110.0(17.0)$ & 179 & $101.6(16.9)$ & $-8.4(-11.9,-4.9)$ & $<0.001$ & $-5.3(-8.4,-2.1)$ & 0.001 \\
\hline \multicolumn{9}{|l|}{ CCC-2 parent } \\
\hline $\begin{array}{l}\text { General communication } \\
\text { composite }\end{array}$ & 176 & $104.7(12.7)$ & 163 & $102.7(13.7)$ & $-2.0(-4.8,0.8)$ & 0.17 & $-0.4(-3.2,2.4)$ & 0.76 \\
\hline SIDI & 176 & $4.5(3.9)$ & 163 & $4.3(3.8)$ & $-0.1(-1.0,0.7)$ & 0.73 & $-0.3(-1.1,0.6)$ & 0.51 \\
\hline \multicolumn{9}{|l|}{ CCC-2 teacher } \\
\hline $\begin{array}{l}\text { General communication } \\
\text { composite }\end{array}$ & 132 & $107.9(13.9)$ & 121 & $104.3(15.8)$ & $-3.6(-7.3,0.1)$ & 0.06 & $-3.2(-6.8,0.5)$ & 0.09 \\
\hline SIDI & 132 & $6.4(5.8)$ & 121 & $5.9(4.1)$ & $-0.5(-1.7,0.7)$ & 0.43 & $-0.7(-2.0,0.7)$ & 0.33 \\
\hline
\end{tabular}

* Adjusted for age (continuous), sex, SES (continuous), and maternal IQ ${ }^{51}$ (continuous).

Seven patients $(4 \%)$ and 2 controls $(1 \%)$ reported a history of hearing services, 13 patients (7\%) and 5 controls $(3 \%)$ reported a history of hearing problems, and 8 patients $(4 \%)$ and 7 controls (4\%) reported a diagnosis of a language disorder. Odds ratios were not estimated for these events due to their infrequency.

Eighty-two patients (46\%) and 67 controls (37\%) received 1 or more intervention services prior to school-age follow-up. Case deficits increased after accounting for interim intervention using censored normal regression, with adjusted group differences ranging from -0.1 to $-0.5 \mathrm{SD}$ (Table 3).

Group differences were not materially changed in sensitivity analyses including adjustment using propensityscore matching, accounting for attrition using inverse probability weighting, or excluding 19 children with known or probable causal genetic mutations for craniosynostosis (data not shown).

\section{Analyses by Diagnostic Subgroup}

Across all suture types (sagittal, metopic, unilateral coronal, and lambdoid synostosis), children with SSC consistently scored more poorly than children without SSC on most subtests of the CMS, NEPSY-II, and WISC-IV, although differences were modest and confidence intervals were wide (Table 4). The magnitude of case-control differences was greatest in children with unilateral coronal compared with other suture groups (Table 5). Parents and teachers of children with sagittal synostosis provided more favorable general communication composite and SIDI scores than controls or children with other suture types. There was some evidence of overall differences in language, learning, and memory scores and parent and teacher scores by the site of the affected suture, in particular for the Stories-immediate and Stories-delayed subtests of the CMS and for WISC-IV verbal comprehension ( $\mathrm{p}<$ 0.05 for group differences).

\section{Discussion}

Given the mixed findings from previous studies, $4,6,9,12$, $13,15,23,34,41,48$ the primary aim of this investigation was to determine whether school-age children with SSC, all of whom underwent cranioplasty, have deficits in language and memory skills in relation to demographically similar children without a craniofacial disorder. Use of a control group for such comparisons is critical but has been rarely 
TABLE 3. Differences between children with and without SSC adjusted for intervention participation

\begin{tabular}{|c|c|c|}
\hline \multirow[b]{2}{*}{ Neurodevelopmental Test } & \multicolumn{2}{|c|}{$\begin{array}{c}\text { Adjusted, w/ Censored } \\
\text { Normal Regression* }\end{array}$} \\
\hline & Difference $(95 \% \mathrm{Cl})$ & p Value \\
\hline Token Test & $-2.5(-5.8,0.7)$ & 0.12 \\
\hline \multicolumn{3}{|l|}{ CMS } \\
\hline \multicolumn{3}{|l|}{ Stories } \\
\hline Immediate & $-1.1(-1.9,-0.3)$ & 0.008 \\
\hline Delayed & $-1.5(-2.4,-0.6)$ & 0.001 \\
\hline Delayed recognition & $-0.4(-1.1,0.4)$ & 0.30 \\
\hline Immediate thematic & $-1.1(-1.9,-0.3)$ & 0.01 \\
\hline Delayed thematic & $-1.3(-2.2,-0.4)$ & 0.004 \\
\hline \multicolumn{3}{|l|}{ Word Lists } \\
\hline Learning & $-1.1(-1.9,-0.2)$ & 0.01 \\
\hline Delayed & $-1.2(-2.1,-0.3)$ & 0.01 \\
\hline Delayed recognition & $-1.2(-2.0,-0.4)$ & 0.005 \\
\hline \multicolumn{3}{|l|}{ NEPSY-II word generation } \\
\hline Semantic total score & $-1.5(-2.3,-0.6)$ & 0.001 \\
\hline Initial letter total score & $-0.8(-1.5,-0.1)$ & 0.03 \\
\hline \multicolumn{3}{|l|}{ WISC-IV } \\
\hline Verbal comprehension & $-7.2(-11.2,-3.2)$ & 0.001 \\
\hline \multicolumn{3}{|l|}{ CCC-2 parent } \\
\hline General communication composite & $-2.2(-6.1,1.6)$ & 0.25 \\
\hline SIDI & $-0.8(-1.7,0.0)$ & 0.05 \\
\hline \multicolumn{3}{|l|}{ CCC-2 teacher } \\
\hline General communication composite & $-4.2(-9.4,1.1)$ & 0.12 \\
\hline SIDI & $-0.5(-2.0,1.0)$ & 0.50 \\
\hline
\end{tabular}

* Adjusted for age (continuous), sex, SES (continuous), and maternal IQ ${ }^{51}$ (continuous); 82 (46\%) of 177 patients and $67(37 \%)$ of 183 controls received 1 or more interventions; information on interventions missing in 2 cases.

undertaken in previous research on this topic. The absence of a demographic control is substantially limiting, as SES is a strong predictor of language outcomes. For example, Fernald et al. ${ }^{16}$ found that by age 5 years the language skills of children from lower socioeconomic backgrounds were delayed by approximately 2 years in comparison with more socially advantaged peers. Similarly we have previously reported sex differences on the neurocognitive measures used in this test battery, ${ }^{13}$ with males in both the case and control groups scoring lower than females from both groups on most measures. Thus, failing to adjust for sex, SES, and other demographic confounding variables may yield misleading results and variation across studies, depending on the population sampled. A secondary aim was to investigate the possibility of differences in language and memory functions by suture location, an issue that has been infrequently addressed in previous studies.

On direct assessment using standardized tests, $77 \%$ of children with SSC and $89 \%$ of the controls in our sample obtained a Verbal Comprehension Index standard score of $\geq 90$. In other words, the majority of children in both groups demonstrated verbal comprehension skills within the low average range or higher relative to test norms.
The average scores for children with SSC were lower than those of unaffected controls for every language and memory test administered, though differences were sometimes quite small. These findings were robust when adjusting for potential demographic and other confounding variables (e.g., maternal IQ) and possible attrition bias, and were magnified when adjusting for the effects of developmental interventions received. These findings are similar to those from our previous study on global cognitive functioning and academic skills reported by Speltz et al ${ }^{43}$ and measures of executive functioning and attention as reported by Collett et al..$^{12}$ As in the current study, group differences on measures of IQ and academic achievement were modest, though children with SSC scored lower than unaffected controls on every measure given. Tests of spelling and reading achievement yielded the smallest differences, with tests of Full-Scale IQ and math achievement indicating larger differences that were educationally important (e.g., patients underperformed in comparison with controls by about one-third of a standard deviation; differences on all measures increased after controlling for early intervention services received) ${ }^{43}$ Collett et al. ${ }^{12}$ also found that children with SSC scored lower than controls on most measures, though again the magnitude of these differences was small and, with the exception of inhibitory control, most differences were statistically insignificant.

In the present study, parent reports revealed the smallest differences in performance between the case and control participants. Parents of both groups reported very similar language skills as indicated by the general language composite score of the CCC-2, which was less than a half point lower for case than for control participants after adjusting for sociodemographic differences. Teacher-reported differences in performance were larger than parent-reported differences, but were still relatively small (SD 0.2). Teacher-reported differences were primarily related to slightly lower scores on the social relations, scripted language, nonverbal communication, and initiation subtests. It is unclear if these very subtle differences between case and control participants have any meaningful impact on the day-to-day functioning of the children, as the average SIDI is well within the expected range for both groups.

The differences in expressive and receptive language that we observed at age 3 years ${ }^{45}$ persisted at age 7 years when direct assessment of child functioning rather than parent or teacher report was used as the measuring stick. Although mean scores were within the average range, children with SSC performed worse on both subtests of the WISC-IV measuring verbal comprehension (i.e., the ability to define words and the ability to identify similarities between words). Poorer performance among children with SSC was also seen on a task of semantic verbal fluency, a measure of language planning and processing.

We assessed verbal memory skills in several different ways. The 2 groups demonstrated equivalent performances on the Token Test-II, which measured the children's ability to follow commands of increasing difficulty immediately after hearing them. In contrast, children with SSC performed less well on verbal learning tasks and when asked to repeat a short story. Children with SSC were less efficient with new learning, remembered fewer facts from 
TABLE 4. Distribution of mean language, learning, and memory scores for children with SSC by suture

\begin{tabular}{|c|c|c|c|c|c|c|c|c|c|c|}
\hline \multirow[b]{3}{*}{ Neurodevelopmental Test } & \multirow{2}{*}{\multicolumn{2}{|c|}{ Controls }} & \multicolumn{8}{|c|}{ Type of SSC } \\
\hline & & & \multicolumn{2}{|r|}{ Sagittal } & \multicolumn{2}{|r|}{ Metopic } & \multicolumn{2}{|c|}{ Unicoronal } & \multicolumn{2}{|c|}{ Lambdoid } \\
\hline & No. & Mean (SD) & No. & Mean (SD) & No. & Mean (SD) & No. & Mean (SD) & No. & Mean (SD) \\
\hline Token Test & 177 & $104.8(12.5)$ & 74 & $102.8(11.1)$ & 44 & $101.8(15.9)$ & 43 & $100.8(12.7)$ & 12 & $101.5(13.4)$ \\
\hline \multicolumn{11}{|l|}{ CMS } \\
\hline \multicolumn{11}{|l|}{ Stories } \\
\hline Immediate & 178 & $11.7(2.7)$ & 74 & $11.1(2.8)$ & 43 & $11.4(2.7)$ & 45 & $9.9(3.0)$ & 10 & $9.8(3.9)$ \\
\hline Delayed & 176 & $11.6(3.1)$ & 74 & $10.8(3.1)$ & 42 & $10.8(3.3)$ & 44 & $9.4(3.5)$ & 10 & $10.0(4.2)$ \\
\hline Delayed recognition & 177 & $10.9(2.6)$ & 74 & $10.9(2.7)$ & 42 & $11.0(2.8)$ & 43 & $10.2(2.7)$ & 10 & $9.6(2.1)$ \\
\hline Immediate thematic & 178 & $11.9(2.9)$ & 74 & $11.1(3.0)$ & 43 & $11.4(2.7)$ & 44 & $10.3(3.0)$ & 10 & $10.9(4.6)$ \\
\hline Delayed thematic & 176 & $11.4(3.0)$ & 74 & $10.6(3.1)$ & 42 & $10.5(3.1)$ & 43 & $9.7(3.5)$ & 10 & $10.3(4.1)$ \\
\hline \multicolumn{11}{|l|}{ Word Lists } \\
\hline Learning & 174 & $10.2(2.8)$ & 74 & $9.6(2.8)$ & 43 & $9.3(3.2)$ & 43 & $9.3(3.2)$ & 9 & $8.4(2.1)$ \\
\hline Delayed & 173 & $10.8(3.1)$ & 74 & $10.4(3.2)$ & 43 & $9.7(3.7)$ & 42 & $9.4(3.5)$ & 10 & $10.5(2.7)$ \\
\hline Delayed recognition & 173 & $10.5(2.6)$ & 74 & $9.5(3.2)$ & 43 & $9.7(3.4)$ & 42 & $10.0(3.2)$ & 10 & $9.3(2.8)$ \\
\hline \multicolumn{11}{|l|}{ NEPSY-II word generation } \\
\hline Semantic total score & 179 & $12.0(3.3)$ & 72 & $11.1(3.0)$ & 45 & $10.7(2.9)$ & 45 & $10.6(3.6)$ & 12 & $10.8(4.5)$ \\
\hline Initial letter total score & 179 & $9.7(2.6)$ & 73 & $9.5(2.7)$ & 45 & $9.3(2.9)$ & 45 & $9.4(2.8)$ & 12 & $8.3(3.5)$ \\
\hline \multicolumn{11}{|l|}{ WISC-IV } \\
\hline Verbal comprehension & 183 & $110.0(17.0)$ & 76 & $104.7(13.5)$ & 45 & $102.2(19.4)$ & 46 & $96.0(17.1)$ & 12 & $102.0(21.8)$ \\
\hline \multicolumn{11}{|l|}{ CCC-2 parent } \\
\hline General communication composite & 176 & $104.7(12.7)$ & 70 & $104.9(13.4)$ & 41 & $100.5(13.3)$ & 40 & $100.8(14.5)$ & 10 & $103.2(13.2)$ \\
\hline SIDI & 176 & $4.5(3.9)$ & 70 & $3.8(3.1)$ & 41 & $4.1(3.6)$ & 40 & $5.1(4.7)$ & 10 & $5.4(5.3)$ \\
\hline \multicolumn{11}{|l|}{ CCC-2 teacher } \\
\hline General communication composite & 132 & $107.9(13.9)$ & 55 & $107.3(14.0)$ & 29 & $100.7(14.9)$ & 27 & $102.6(20.3)$ & 10 & $103.1(12.3)$ \\
\hline SIDI & 132 & $6.4(5.8)$ & 55 & $4.6(3.3)$ & 29 & $6.6(3.8)$ & 27 & $6.8(4.6)$ & 10 & $8.7(5.5)$ \\
\hline
\end{tabular}

the stories, and were less skilled at identifying themes within the stories, suggesting that they were less able to integrate the information they heard. Verbal learning and story memory were poorer both immediately after presentation and after a short delay. Verbal memory did not differ between cases and controls when children were given choices about story facts.

When examining differences in performance among children with different suture fusions, we found that children from each suture group obtained lower scores than control participants on each of the tests assessing language and memory for which significant case-control differences were present. The differences in performance were quite small when comparing children with sagittal, metopic, and unilateral lambdoid synostosis to control participants but meaningful for a number of measures comparing children with unilateral coronal synostosis to control participants. For example, compared with control participants, children with unilateral coronal synostosis had poorer verbal comprehension skills, lower scores on story memory and identification of story themes, and lower language scores based on their parents' and teachers' reports compared with control children. We have previously reported on differences in performance by suture group, identifying children with unilateral coronal and unilateral lambdoid synostosis as at greatest risk..$^{13,43}$ A report by Chieffo et al. ${ }^{9}$ is the only other study to date that has directly assessed and compared the performance of school-aged children with different suture involvement in the same study, although these authors only included children with sagittal and unilateral coronal synostosis. ${ }^{9}$ Similar to our findings, Chieffo et al. ${ }^{9}$ reported poorer verbal fluency and working memory for children with unilateral coronal synostosis compared with children with sagittal SSC and the control participants.

As this was an observational study, primarily designed to determine the relative outcomes of children with and without SSC, we did not make any attempt to influence treatment decisions or randomize subjects by age or type of surgery. Rather, we tracked children as they received care typical of the setting in which they were seen. As such, the study's design is limited in its ability to elucidate the mechanisms by which SSC or factors associated with SSC (e.g., surgery and anesthesia exposure ${ }^{35}$ ) have led to the group differences observed here and elsewhere..$^{4,6,9,13,15,23,34,41,48}$ The etiology of the neurodevelopmental consequences and correlates of SSC remains unclear, with some hypotheses focusing on the effects of the fused suture on brain development ${ }^{1-3,47,49}$ and others 


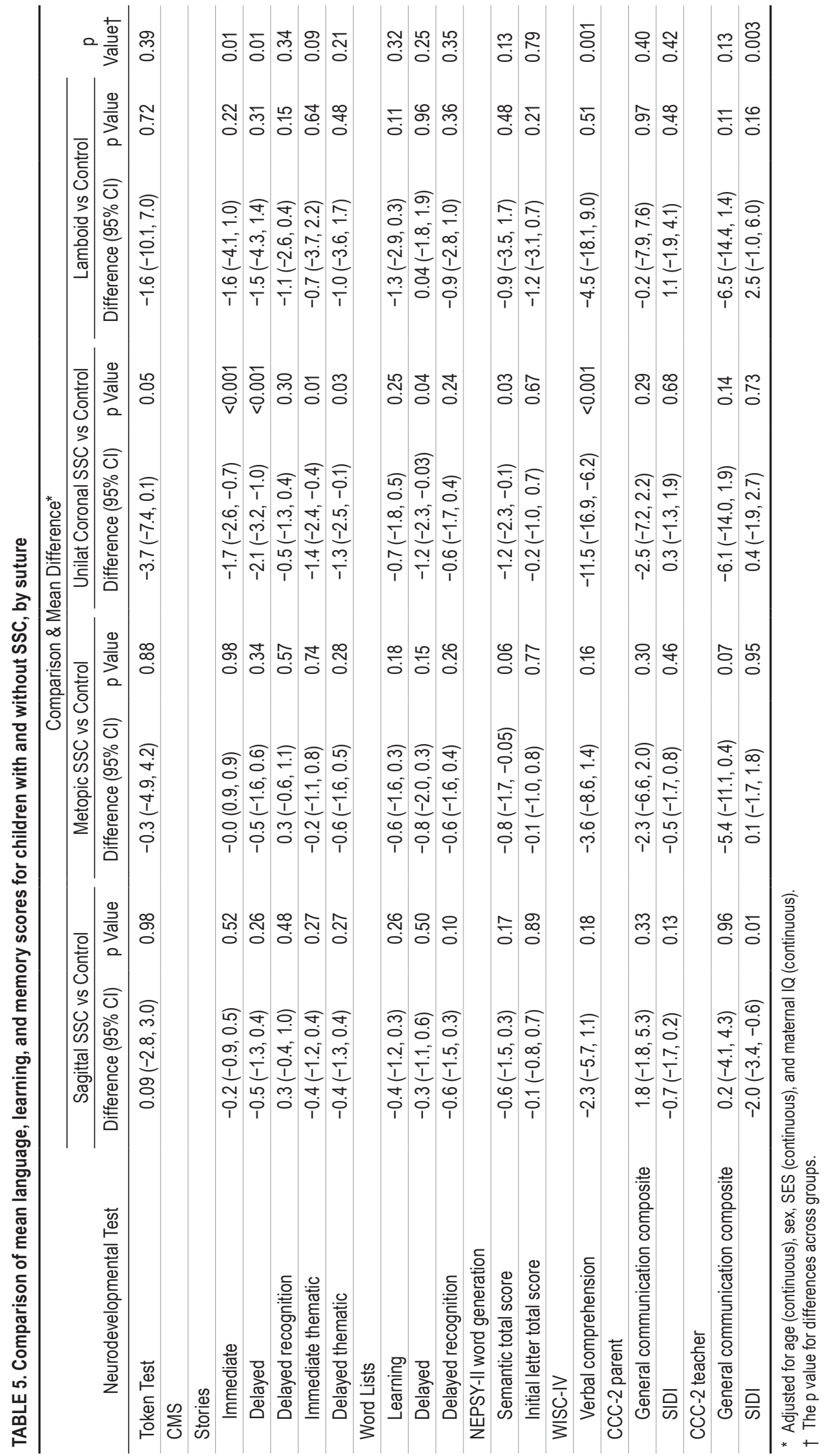


emphasizing preexisting neuropathology that may affect both brain and cranium. ${ }^{5,19}$ These studies provide some evidence that changes in brain morphology present prior to surgery persist after surgery. ${ }^{2}$ There is also evidence that changes in auditory functioning, potentially related to later language and literacy development, ${ }^{29,37}$ are present prior to surgical intervention for infants with SSC. ${ }^{19}$ Functional changes in brain circuitry known to be associated with language and number processing, memory retrieval, and reading have been identified in older children with sagittal SSC who underwent surgery as infants. ${ }^{5}$ Further research examining brain morphology and function prior to and after cranioplasty is needed to clarify these issues.

Previous studies have proposed that variables related to surgery, including age at surgery, ${ }^{24,36,39,45}$ duration of anesthesia exposure,${ }^{35}$ and surgical approach used, ${ }^{20}$ may affect outcomes. However, these results are mixed and warrant further investigation in prospective studies that account for the effects of multiple variables in combination. For example, if suture fusion leads to neurodevelopmental deficits via constriction on brain growth or increased intracranial pressure, earlier surgery should be advantageous. However, age at surgery is potentially confounded with numerous other variables that might be associated with development, such as family SES, initial severity, surgical approach used, and duration. For example, surgeries at younger ages may well provide optimal benefits in terms of earlier suture release, ${ }^{20,39}$ but less mature brains may be more susceptible to the neurotoxicity associated with anesthesia exposure ${ }^{38}$ In our own work, we have found little association between surgery age and neurodevelopmental outcomes measured both in infancy ${ }^{45}$ and at school age ${ }^{12}$ when controlling for potential confounding variables such as maternal IQ, SES, and involved suture. Work is currently under way in our lab to further disentangle these multiple and complex associations with neurodevelopmental outcomes.

The current research has at least 2 limitations that are important to note. First, in keeping with good ethical practice, we provided parents of both patients and controls with feedback about their children's performance at each visit, which may have influenced the number of children from each group receiving special education services prior to the early elementary school evaluation. This may be especially true for control children, who would not otherwise have been screened for developmental delays. However, we used the same protocol for providing feedback to children in both groups, and our censored normal regression analyses suggest that, if anything, the differences between case and control performance would have increased without intervention. A second limitation is the relatively high sociodemographic profile of the participants, both those originally enrolled and more markedly for those who participated in the school-age assessment. Inverse probability weighting analysis, which used baseline data for available case and control participants to evaluate attrition bias, did not result in significantly different regression outcomes. However, while inverse probability weighting attempts to match for characteristics that influence outcomes such as maternal IQ, family SES, and ethnicity, it cannot control for the less tangible factors that influence a family's will- ingness to participate in up to 4 extensive evaluations. It is very possible that children from lower SES groups would demonstrate increased risk over those included in the current study.

This study also has several important strengths including the examination of learning, language, and memory skills through multiple, direct assessments as well as parent and teacher reports, and the comparison of children with SSC to unaffected control children with adjustment for potential confounders (e.g., maternal IQ, demographic characteristics). Although this is a "clinic-based" rather than a "population-based" study, we reassessed children who were identified in infancy regardless of whether they continued to be followed up by the craniofacial team or not; this increases the generalizability of our findings to a broader range of children with SSC. In addition, recruitment in early infancy minimizes enrollment bias associated with infants' developmental status (i.e., compared with older children with SSC who might be more likely to participate in research when there are developmental concerns). Finally, we employed sensitivity analyses to account for the possible effects of attrition bias and developmental interventions that participants received in their communities.

\section{Conclusions}

Our data provide evidence of modest differences between cases and controls in language and memory consistent with those that have been reported in the literature for children with SSC. These small differences do not appear to be particularly apparent in the day-to-day functioning of children with SSC as reported by parents or teachers, with the possible exception of children with unilateral coronal synostosis. However, among a sizable subgroup of children with SSC, there is evidence of poorer functioning on direct assessment, particularly on tasks that require consolidation of learning and memory. These findings may have implications for increasing problems with school performance as these children mature. The children in this study are still young, age 7 years on average, and therefore continued maturation of the neural pathways that support language, learning, and memory development are expected ${ }^{10,28}$ If there is a primary disruption in brain networks, as suggested by the preliminary work of Aldridge et al., ${ }^{1-3}$ Beckett et al., ${ }^{5}$ and Hashim et al., ${ }^{19}$ or if anesthesia exposure affects brain development, ${ }^{35,38}$ problems with language and memory may become more apparent and have a greater effect on learning as children approach middle- and high-school age due to possible ongoing disruption of neural networks as they age.

Our findings have implications for the clinical management of children with SSC. Multidisciplinary care, including direct psychological/neuropsychological assessment, is indicated for children with SSC of elementary-school age, as problems with language and conceptual learning may not be evident until children face greater academic challenges. This recommendation is in keeping with that put forth in the recently developed craniosynostosis care guidelines. ${ }^{32}$ The current study identifies children with unilateral coronal synostosis as having the greatest vul- 
nerability in the areas of language, memory, and learning; however, selective screening of children with all SSC diagnosis is indicated, as some children in each diagnostic group were at risk. Neurodevelopmental assessment at 18 months of age may help identify those children requiring closer follow-up through school age. ${ }^{18}$ Finally, future research is needed to investigate language, memory, and learning for this population during the middle to high school years.

\section{Acknowledgments}

We thank Sharman Conner, Claudia Crilly Bellucci, and Dr. Lauren Buono for their assistance in data collection. We thank the parent and child participants who gave so willingly of their time and energy to this research. This research was supported by the National Institute of Dental and Craniofacial Research under Grant 5R01DE013813-10 (Dr. Speltz served as the head principal investigator).

\section{References}

1. Aldridge K, Kane AA, Marsh JL, Panchal J, Boyadjiev SA, Yan P, et al: Brain morphology in nonsyndromic unicoronal craniosynostosis. Anat Rec A Discov Mol Cell Evol Biol 285:690-698, 2005

2. Aldridge K, Kane AA, Marsh JL, Yan P, Govier D, Richtsmeier JT: Relationship of brain and skull in pre- and postoperative sagittal synostosis. J Anat 206:373-385, 2005

3. Aldridge K, Marsh JL, Govier D, Richtsmeier JT: Central nervous system phenotypes in craniosynostosis. J Anat 201:31-39, 2002

4. Becker DB, Petersen JD, Kane AA, Cradock MM, Pilgram TK, Marsh JL: Speech, cognitive, and behavioral outcomes in nonsyndromic craniosynostosis. Plast Reconstr Surg 116:400-407, 2005

5. Beckett JS, Brooks ED, Lacadie C, Vander Wyk B, Jou RJ, Steinbacher DM, et al: Altered brain connectivity in sagittal craniosynostosis. J Neurosurg Pediatr 13:690-698, 2014

6. Bellew M, Liddington M, Chumas P, Russell J: Preoperative and postoperative developmental attainment in patients with sagittal synostosis: 5-year follow-up. J Neurosurg Pediatr 7:121-126, 2011

7. Bishop DVM: Children's Communication Checklist-2 (CCC-2). San Antonio, TX: Pearson, 2006

8. Boltshauser E, Ludwig S, Dietrich F, Landolt MA: Sagittal craniosynostosis: cognitive development, behaviour, and quality of life in unoperated children. Neuropediatrics 34:293-300, 2003

9. Chieffo D, Tamburrini G, Massimi L, Di Giovanni S, Giansanti C, Caldarelli M, et al: Long-term neuropsychological development in single-suture craniosynostosis treated early. J Neurosurg Pediatr 5:232-237, 2010

10. Clayden JD, Jentschke S, Muñoz M, Cooper JM, Chadwick MJ, Banks T, et al: Normative development of white matter tracts: similarities and differences in relation to age, gender, and intelligence. Cereb Cortex 22:1738-1747, 2012

11. Cohen M: Children's Memory Scale (CMS). San Antonio, TX: The Psychological Corporation, 1997

12. Collett BR, Kapp-Simon KA, Wallace E, Cradock MM, Buono L, Speltz ML: Attention and executive function in children with and without single-suture craniosynostosis. Child Neuropsychol [epub ahead of print], 2015

13. Cradock MM, Gray KE, Kapp-Simon KA, Collett BR, Buono LA, Speltz ML: Sex differences in the neurodevelopment of school-age children with and without single-suture craniosynostosis. Childs Nerv Syst 31:1103-1111, 2015

14. Cunningham ML, Horst JA, Rieder MJ, Hing AV, Stan- away IB, Park SS, et al: IGF1R variants associated with isolated single suture craniosynostosis. Am J Med Genet A 155A:91-97, 2011

15. Da Costa AC, Walters I, Savarirayan R, Anderson VA, Wrennall JA, Meara JG: Intellectual outcomes in children and adolescents with syndromic and nonsyndromic craniosynostosis. Plast Reconstr Surg 118:175-183, 2006

16. Fernald A, Marchman VA, Weisleder A: SES differences in language processing skill and vocabulary are evident at 18 months. Dev Sci 16:234-248, 2013

17. French LR, Jackson IT, Melton LJ III: A population-based study of craniosynostosis. J Clin Epidemiol 43:69-73, 1990

18. Gray KE, Kapp-Simon KA, Starr JR, Collett BR, Wallace ER, Speltz ML: Predicting developmental delay in a longitudinal cohort of preschool children with single-suture craniosynostosis: is neurobehavioral assessment important? Dev Med Child Neurol 57:456-462, 2015

19. Hashim PW, Brooks ED, Persing JA, Reuman H, Naples A, Travieso R, et al: Direct brain recordings reveal impaired neural function in infants with single-suture craniosynostosis: a future modality for guiding management? J Craniofac Surg 26:60-63, 2015

20. Hashim PW, Patel A, Yang JF, Travieso R, Terner J, Losee JE, et al: The effects of whole-vault cranioplasty versus strip craniectomy on long-term neuropsychological outcomes in sagittal craniosynostosis. Plast Reconstr Surg 134:491-501, 2014

21. Hollingshead HB: Four factor index of social status. Yale J Sociology 8:21-51, 2011

22. Kapp-Simon KA, Speltz ML, Cunningham ML, Patel PK, Tomita T: Neurodevelopment of children with single suture craniosynostosis: a review. Childs Nerv Syst 23:269-281, 2007

23. Kelleher MO, Murray DJ, McGillivary A, Kamel MH, Allcutt D, Earley MJ: Behavioral, developmental, and educational problems in children with nonsyndromic trigonocephaly. $\mathbf{J}$ Neurosurg 105 (5 Suppl):382-384, 2006

24. Knight SJ, Anderson VA, Spencer-Smith MM, Da Costa AC: Neurodevelopmental outcomes in infants and children with single-suture craniosynostosis: a systematic review. Dev Neuropsychol 39:159-186, 2014

25. Korkman M, Kirk U, Kemp S: NEPSY-II: A Developmental Neuropsychological Assessment, ed 2. San Antonio, TX: The Psychological Corporation, 2007

26. Korpilahti P, Saarinen P, Hukki J: Deficient language acquisition in children with single suture craniosynostosis and deformational posterior plagiocephaly. Childs Nerv Syst 28:419-425, 2012

27. Lefaivre MJ, Chambers CT, Fernandez CV: Offering parents individualized feedback on the results of psychological testing conducted for research purposes with children: ethical issues and recommendations. J Clin Child Adolesc Psychol 36:242-252, 2007

28. Lenroot RK, Giedd JN: The structural development of the human brain as measured longitudinally with magnetic resonance imaging, in Coch D, Fischer KW, Dawson G (eds): Human Behavior, Learning, and the Developing Brain: Typical Development. New York: Guilford Press, 2007, pp 50-73

29. Leppänen PH, Hämäläinen JA, Salminen HK, Eklund KM, Guttorm TK, Lohvansuu K, et al: Newborn brain event-related potentials revealing atypical processing of sound frequency and the subsequent association with later literacy skills in children with familial dyslexia. Cortex 46:1362-1376, 2010

30. Leppig KA, Werler MM, Cann CI, Cook CA, Holmes LB: Predictive value of minor anomalies. I. Association with major malformations. J Pediatr 110:531-537, 1987

31. Magge SN, Westerveld M, Pruzinsky T, Persing JA: Longterm neuropsychological effects of sagittal craniosynostosis on child development. J Craniofac Surg 13:99-104, 2002 
32. McCarthy JG, Warren SM, Bernstein J, Burnett W, Cunningham ML, Edmond JC, et al: Parameters of care for craniosynostosis. Cleft Palate Craniofac J 49 Suppl:1S-24S, 2012

33. McGhee RL, Ehrler DJ, Disimoni F: Token Test for Children-Second Edition Austin, TX: Pro-Ed, 2007

34. Mendonca DA, White N, West E, Dover S, Solanki G, Nishikawa $\mathrm{H}$ : Is there a relationship between the severity of metopic synostosis and speech and language impairments? J Craniofac Surg 20:85-89, 2009

35. Naumann HL, Haberkern CM, Pietila KE, Birgfeld CB, Starr JR, Kapp-Simon KA, et al: Duration of exposure to cranial vault surgery: associations with neurodevelopment among children with single-suture craniosynostosis. Paediatr Anaesth 22:1053-1061, 2012

36. Patel A, Yang JF, Hashim PW, Travieso R, Terner J, Mayes LC, et al: The impact of age at surgery on long-term neuropsychological outcomes in sagittal craniosynostosis. Plast Reconstr Surg 134:608e-617e, 2014

37. Plakas A, van Zuijen T, van Leeuwen T, Thomson JM, van der Leij A: Impaired non-speech auditory processing at a pre-reading age is a risk-factor for dyslexia but not a predictor: an ERP study. Cortex 49:1034-1045, 2013

38. Rappaport BA, Suresh S, Hertz S, Evers AS, Orser BA: Anesthetic neurotoxicity-clinical implications of animal models. N Engl J Med 372:796-797, 2015

39. Renier D, Lajeunie E, Arnaud E, Marchac D: Management of craniosynostoses. Childs Nerv Syst 16:645-658, 2000

40. Robins JM, Rotnitzky A, Zhao LP: Estimation of regression coefficients when some regressors are not always observed. J Am Stat Assoc 89:846-866, 1994

41. Shipster C, Hearst D, Somerville A, Stackhouse J, Hayward $\mathrm{R}$, Wade A: Speech, language, and cognitive development in children with isolated sagittal synostosis. Dev Med Child Neurol 45:34-43, 2003

42. Shuper A, Merlob P, Grunebaum M, Reisner SH: The incidence of isolated craniosynostosis in the newborn infant. Am J Dis Child 139:85-86, 1985

43. Speltz ML, Collett BR, Wallace ER, Starr JR, Cradock MM, Buono L, et al: Intellectual and academic functioning of school-age children with single-suture craniosynostosis. Pediatrics 135:e615-e623, 2015

44. Speltz ML, Kapp-Simon K, Collett B, Keich Y, Gaither R, Cradock MM, et al: Neurodevelopment of infants with single-suture craniosynostosis: presurgery comparisons with case-matched controls. Plast Reconstr Surg 119:1874-1881, 2007

45. Starr JR, Collett BR, Gaither R, Kapp-Simon KA, Cradock MM, Cunningham ML, et al: Multicenter study of neurodevelopment in 3-year-old children with and without single-suture craniosynostosis. Arch Pediatr Adolesc Med 166:536-542, 2012

46. Starr JR, Kapp-Simon KA, Cloonan YK, Collett BR, Cradock MM, Buono L, et al: Presurgical and postsurgical assessment of the neurodevelopment of infants with singlesuture craniosynostosis: comparison with controls. J Neurosurg 107 (2 Suppl):103-110, 2007

47. Thompson DN, Malcolm GP, Jones BM, Harkness WJ, Hayward RD: Intracranial pressure in single-suture craniosynostosis. Pediatr Neurosurg 22:235-240, 1995

48. Virtanen R, Korhonen T, Fagerholm J, Viljanto J: Neurocognitive sequelae of scaphocephaly. Pediatrics 103:791-795, 1999

49. Wall SA, Thomas GP, Johnson D, Byren JC, Jayamohan J, Magdum SA, et al: The preoperative incidence of raised intracranial pressure in nonsyndromic sagittal craniosynostosis is underestimated in the literature. J Neurosurg Pediatr 14:674-681, 2014

50. Wechsler D: Wechsler Intelligence Scale for Children (WISC-IV). San Antonio, TX: Harcourt Assessment, 2003

51. Wonderlic E: Wonderlic Personnel Test and Scholastic Level Exam User's Manual. Libertyville, IL: Wonderlic, Inc., 1999

\section{Disclosures}

The authors report no conflict of interest concerning the materials or methods used in this study or the findings specified in this paper.

\section{Author Contributions}

Conception and design: Kapp-Simon, Speltz. Acquisition of data: Kapp-Simon, Cradock, Crerand, Speltz. Analysis and interpretation of data: Kapp-Simon, Wallace, Speltz. Drafting the article: Kapp-Simon. Critically revising the article: all authors. Reviewed submitted version of manuscript: all authors. Approved the final version of the manuscript on behalf of all authors: Kapp-Simon. Statistical analysis: Wallace. Study supervision: Kapp-Simon, Speltz.

\section{Correspondence}

Kathleen A. Kapp-Simon, Cleft-Craniofacial Clinic, Shriners Hospital for Children, 2211 N. Oak Park Ave., Chicago, IL 60707.email:kkapps@uic.edu. 